American Journal of Applied Sciences 4 (4): 229-232, 2007

ISSN 1546-9239

(C) 2007 Science Publications

\title{
A Comparison Between the New and the Old Versions of Jordan Seismic Code
}

\author{
M. A. Musmar \\ Department of Civil Engineering, Faculty of Engineering Technology \\ AlBalqa'a Applied University, Jordan
}

\begin{abstract}
The study comes as a vital step to shed120 light upon the purport of the recently published version of Jordan Seismic code (JSC), and how the drawbacks of the old version are surpassed. The new JSC code oversteps the old provisions, in that input parameters now have pronounced and significant physical meanings. The study concludes that the conversion from service load to ultimate load calculations was clearly the most significant change. The new JSC code was based on UBC 97 code, but it was tuned to comply with building experiences and conditions existing in Jordan. The new JSC code gives V/W values that are lower by $40 \%$ to $50 \%$ than that of the old JSC code, depending on the period of the structure. The importance of this study was that it asserts the credibility of the new JSC code provisions in that they cope with the real structural response against seismic action, and that the ductility of the structure was directly proportional to its height. The current study tackles the static force procedure. To compare the outcomes in both versions in principle, the study focuses on Amman district. Nevertheless the conclusions hold on for all the regions in Jordan. The study also concludes that the recent JSC code gives far more realistic results than the previous version.
\end{abstract}

Key words: Earthquake engineering, seismic codes, design response spectra, base shear

\section{INTRODUCTION}

The purpose of building codes is to promote and protect the public welfare. Building code provisions, governing design for earthquake resistance, may be traced back as far as building regulation enacted in Lisbon, Portugal, following the great earthquake of $1755^{[1]}$

Early building code provisions for seismic resistance focused on prohibiting certain types of construction observed to behave poorly in past earthquakes, and to require the use of certain construction details and techniques observed to provide better performance. Modern codes supplement these prescriptive requirements with specifications of minimum permissible structural strength and stiffness $^{[2]}$. Current building code provisions for earthquake resistant design do not intend that structures be capable of resisting design loading within the elastic range of response only, in fact some level of damage is permitted.

Earthquakes are highly random and oscillatory in nature. If large enough, the aftermath is dramatic on structures integrity. Thus most earthquake prone regions have developed and adopted local building code provisions.

Building code provisions for earthquake are generally based on three factors. The first is the experience obtained from the observations of the response of real structures when subjected to earthquakes, and the continuous development of prescriptive rules to prevent construction of buildings with characteristics that are observed to result in undesirable behavior. The second is the findings of analytical and laboratory researches, which provide an understanding of the way structures, respond to earthquakes. The third is the building design community that has a vital and dominant contribution in the development of building code provisions.

The recent seismic codes acknowledge that there are certain basic concepts to be recognized in order, first, to understand the nature of the earthquake problem and second, to properly cope with the problem in design of reinforced concrete structures. These have to do with the earthquake demands, the structural capacity, and the fact that reinforced concrete may be designed to be ductile and have great energy dissipation capacity prior to failure ${ }^{[3]}$. The procedures and limitations for the design of structures by such codes are determined considering Zoning, site characteristics, occupancy, configuration, structural system and height.

Many of local building codes have benefited from UBC provisions in formulating their $\operatorname{codes}^{[4]}$. The new Jordan seismic code is no exception. It is based on UBC seismic provisions. It addresses strength level design rather than service design. This complies with the new design procedures that aim to ensure ductility and energy dissipation. New Code provisions are dictated to ensure that shear or compression failure in the concrete flexural members cannot occur prior to stretching of tensile bars, and in compression members, shear failure must not occur. Any concrete that fails in compression is to be confined.

Research Significance: Jordan lies within a zone that is susceptible to seismic hazard. Thus it is of utmost importance to have JSC code provisions that could grant structures, maximum affordable safety. This study

Corresponding Author: $\quad$ M. A. Musmar, Department of Civil Engineering, Faculty of Engineering Technology, AlBalqa'a Applied University, Jordan 
Am. J. Appl. Sci., 4 (4): 229-232, 2007

Table 1: Comparison of base shear equations for the old and new seismic code

\begin{tabular}{|c|c|}
\hline Old seismic code & New seismic code \\
\hline $\begin{array}{l}V=\alpha \cdot \beta \cdot \delta \cdot \theta \cdot \eta \cdot \sum_{Z=1}^{n}\left(\gamma_{Z} \cdot W_{Z}\right) \\
\text { factor } \beta=\text { dynamic factor } \delta=\text { soil factor } \theta=\text { behavior factor } \eta= \\
\text { importance factor } \gamma_{\mathrm{Z}}=\text { height factor } W z=\text { seismic dead load for the } \\
\mathrm{Z}^{\text {th }} \text { story }\end{array}$ & $\begin{array}{l}\frac{2.5 C_{a} I}{R} W_{D} \geq V=\frac{C_{V} I}{R T_{a}} W_{D} \geq 0.1 C_{a} I W_{D} \\
\text { seismic coefficient } C_{v}=\text { velocity dependent seismic coefficient } I= \\
\text { seismic Importance factor } W=\text { seismic dead load } R=\text { response } \\
\text { modification factor } Z=\text { seismic Zone factor } T \alpha=\text { structural period }\end{array}$ \\
\hline
\end{tabular}

Table 2: Design parameters for the case study relevant to recent and old versions of Jordan seismic code

\begin{tabular}{llll}
\hline \multicolumn{2}{l}{ New seismic code } & \multicolumn{2}{l}{ Old seismic code } \\
\hline City & Amman & City & Amman \\
\hline Seismic Zone & $2 \mathrm{~A}$ & Seismic Zone & $\mathrm{B}$ \\
$\mathrm{Z}$ & 0.12 & $\alpha$ & 0.5 \\
$\mathrm{I}$ & 1 & $\eta$ & 1 \\
$\mathrm{Ca}$ & 0.18 & $\beta$ & 0.1 \\
$\mathrm{Cv}$ & 0.25 & $\delta$ & 0.8 \\
$\mathrm{R}$ & 3.5 &.$\theta$ & 1.33 \\
\hline
\end{tabular}

tackles the static force procedure. It comes as a vital step to shed light upon the purport of publishing the new JSC code version, and how the drawbacks of the old version provisions are surpassed. The study concludes that the new JSC code approach copes with ultimate load calculations and the strength design procedures. Whereas the old JSC code outcomes may only be implemented with the service load calculations and the obsolete working stress design methods.

Comparative analyses: Comparison between the two codes necessitates discussing the following main titles:

Zones: The old JSC code categorizes four seismic zones for Jordan whereas the new JSC code presents five categories of seismic zones

Table 3: The different zones that Jordan lies in.

\begin{tabular}{cccc}
\multicolumn{2}{c}{ Old seismic code } & \multicolumn{2}{c}{ New seismic code } \\
Zone & Intensity factor & Zone & $\begin{array}{c}\text { Seismic zone } \\
\text { factor Z }\end{array}$ \\
\hline A & $\alpha$ & & - \\
$\mathrm{B}$ & 0.75 & 0 & 0.075 \\
$\mathrm{C}$ & 0.5 & 1 & 0.15 \\
$\mathrm{D}$ & 0.3 & $2 \mathrm{~A}$ & 0.2 \\
& 0.1 & $2 \mathrm{~B}$ & 0.3 \\
\hline
\end{tabular}

Lateral load calculations: The new Jordan seismic code lateral load calculations address strength design level rather than service design. This measure complies with the current design philosophy that goes beyond the elastic response stage.

Soil profile types: The recent JSC contains six profile types, $\mathrm{S}_{\mathrm{A}}$ to $\mathrm{S}_{\mathrm{F}}$. They are based on soil characteristics for the top $30 \mathrm{~m}$ of soil. The properties used to identify the soil profile type are the shear wave velocity, standard penetration test, and undrained shear strength. Both the acceleration dependent seismic coefficient $\mathrm{Ca}$, and the velocity dependent seismic coefficient $\mathrm{Cv}$, used in determining the base shear depend on the soil profile type, contrary to the case in old JSC. This is more realistic and appropriate. It is in accordance with the recent data which manifest site factors as actually nonlinear and depend on both the zone factor, and the site soil characteristic termed zone factor ${ }^{[4]}$.

Structural framing systems: In addition to presenting four main structural systems with respect to response criterion, the new JSC code acknowledges the most common structural system prevailing in Jordan. This system primarily consists of stone walls overlaid by concrete walls. In this regard, detailed and suitable provisions are employed.

Base shear (V) equations: Table 1 lists the parameters adopted by old seismic code in column 1, and parameters embodied by new seismic code in column 2 .

In order to obtain tangible results, a case study is adopted. It comprises a model structure that consists of ordinary moment resisting frames. It is located in Amman. The grid plan is as shown in Fig. 1. The story height is four meters. The number of stories varies from one up to twenty stories.

The base shear is calculated, first according to recent JSC code, then according to the old JSC provisions. Table 2 shows the input parameters utilized to calculate base shear according to each provision. The obtained results are shown in Fig. 2 and 3.

It is noticed in Fig. 2 that curve illustrating new JSC code output for $\mathrm{V} / \mathrm{W}$ values is in close agreement with UBC97 design response spectra. It is worthwhile to mention that UBC97 design response spectra have been adopted in the United States as a result of extensive studies, laboratory testing and observations of the response of real structures, subjected to earthquakes. The second curve for $\mathrm{V} / \mathrm{W}$ values is derived from old JSC provisions. Figure 2 and 
Fig. 3 show that the two curves are not in agreement. In fact the old JSC code gives larger values of V/W for higher structural periods. This is incorrect considering the fact that the taller building is, the lower the structural stiffness values and $\mathrm{V} / \mathrm{W}$ values are. The new JSC code gives V/W values that are $40 \%$ to $50 \%$ lower than the old JSC code values.

The discrepancy between Fig. 1 and 2 is attributed to the fact that new JSC code provisions yield structural period values, different from those obtained using old JSC provisions.

Code material content: The new JSC code contains conditions and methods of seismic force calculations for buildings subjected to earthquake excitation. It also presents seismic design methods for different structural elements in addition to the proper detailing to ensure structural integrity. In chapter six in new JSC code a simplified method to calculate design base shear is presented. This method is applicable for a large portion of building constructions in Jordan, whereas the old version is very limited and only embodies simple lateral load calculations.

The new JSC code adopts a general simple, realistic equation to calculate the period of structures,

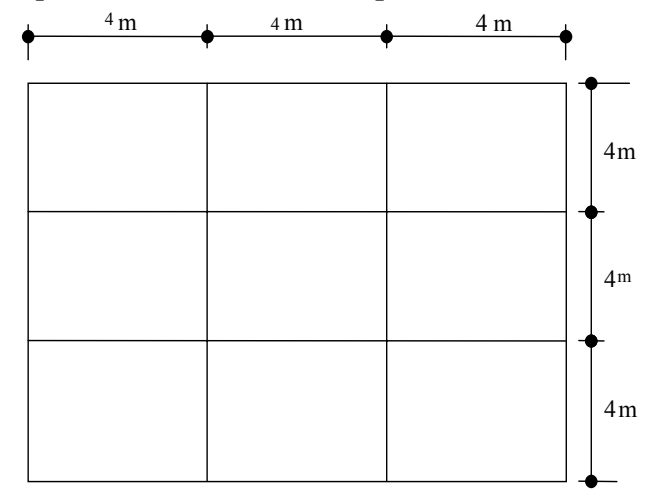

Fig. 1: Grid plan of model structure

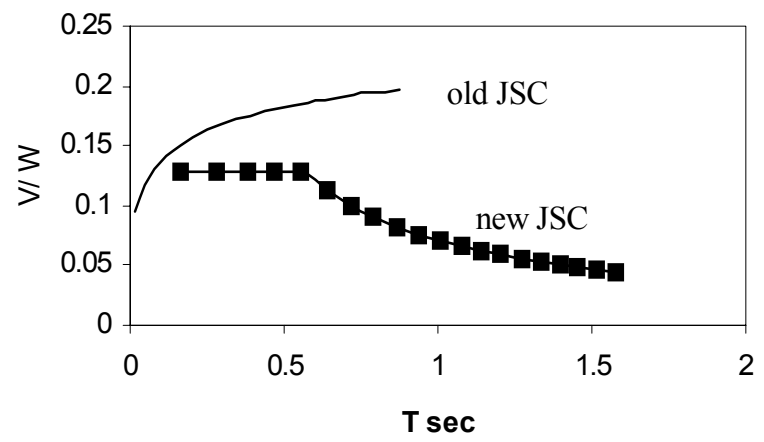

Fig. 2: Period of structure in sec versus V/W

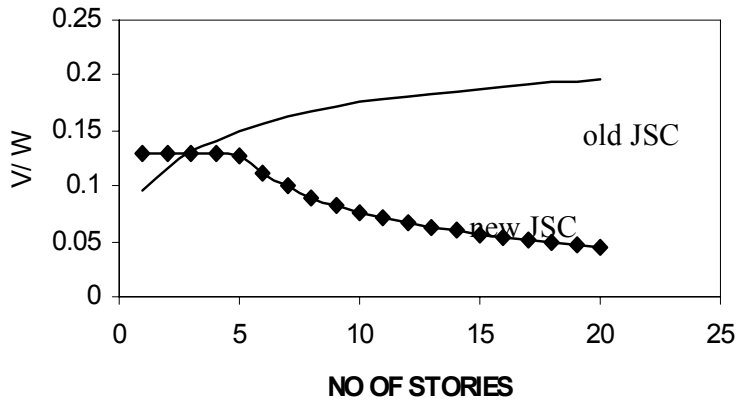

Fig. 3: Number of stories versus $\mathrm{V} / \mathrm{W}$

based on extensive global studies, laboratory testing and observation of the response of real structures, subjected to earthquakes.

\section{CONCLUSION}

This study has concluded the following:

1. The old seismic provisions lacked proficiency. It also failed to cover major issues regarding earthquake impact, structural response or constructional provisions and detailing to assert ample structural integrity upon earthquake action.

2. The new seismic code addresses strength design rather than service design level. It better complies with current design philosophy for earthquake resistant structures, which goes past the elastic response stage.

3. With respect to old JSC seismic provisions, the new building code provisions provide $40 \%$ to $50 \%$ lower $\mathrm{V} / \mathrm{W}$ values for structures of height exceeding four stories, acknowledging the fact that the taller the building is, the larger the period is, and the lower the structural rigidity is. Whereas the old version erroneously gives larger values of $\mathrm{V} / \mathrm{W}$ for higher structural periods.

4. It is also noticed that all new parameters such as acceleration dependent seismic coefficients $\mathrm{Ca}$, velocity dependent seismic coefficients $\mathrm{Cv}$, response modification factor $\mathrm{R}$ have pronounced and significant physical meanings. The parameters $\mathrm{Ca}, \mathrm{Cv}$ are functions of the soil type and seismic zone factor. The result is obtaining more realistic base shear values. 
5. The new seismic code covers conditions and methods of seismic force calculations for buildings subjected to earthquake excitation. It also addresses the commonly used stonewall structures in buildings in Jordan.

6. The new seismic code is based on Uniform Building Code UBC97, but it is tuned to comply with building experience and conditions existing in Jordan.

7. The study recommends that further studies are to be carried out to understand the effect of stonewalls and other structural and nonstructural elements that are common in Jordan on the outcomes of the static force procedure provisions presented in new JSC code.

\section{REFERENCES}

1. Tobriner, S., 1984. The History of Building Codes to the 1920s. Proc. SEAOC, Sacramento.

2. Chen, W.F. and C. Scawthorn, 2003. Earthquake Engineering Handbook.

3. Blume, J.A., 1970. Design of Earthquake-Resistant Poured in Place Concrete Structures. Earthquake Engineering, R.L. Wiegel, Ed., Prentice-Hall, Englewood Cliffs, NJ, Chapter 18.

4. David, A.F. and J.A. Munshi, 1997. Design of Concrete Buildings For Earthquake and Wind Forces, According To The 1997 Uniform Building Code. 